\title{
The Global Climate and Energy Project at Stanford University: Fundamental Research Towards Future Energy Technologies
}

\author{
Jennifer L. MILNE*, Richard E. SASSOON*, Emilie HUNG*, \\ Paolo BOSSHARD** and Sally M. BENSON***
}

\begin{abstract}
The Global Climate and Energy Project (GCEP), at Stanford University, invests in research with the potential to lead to energy technologies with lower greenhouse gas emissions than current energy technologies. GCEP is sponsored by four international companies, ExxonMobil, GE, Schlumberger, and Toyota and supports research programs in academic institutions worldwide. Research falls into the broad areas of carbon based energy systems, renewables, electrochemistry, and the electric grid. Within these areas research efforts are underway that are aimed at achieving break-throughs and innovations that greatly improve efficiency, performance, functionality and cost of many potential energy technologies of the future including solar, batteries, fuel cells, biofuels, hydrogen storage and carbon capture and storage. This paper presents a summary of some of GCEP's activities over the past 7 years with current research areas of interest and potential research directions in the near future.
\end{abstract}

\section{Background}

The Global Climate and Energy Project (GCEP) at Stanford University seeks to find new solutions to one of the most significant challenges of this century - supplying energy to meet the changing needs of a growing population while protecting the environment. This is a unique industry-university partnership launched in 2002 and supported by four international companies: ExxonMobil, GE, Schlumberger, and Toyota. GCEP primary efforts fall into two complementary categories: Research and Analysis.

The research part of GCEP is a major effort that involves investment in fundamental sci- entific research that will provide the foundation for sustained technological innovation. With initial funding of $\$ 225$ million, GCEP has helped to unleash the creativity of faculty and students at Stanford and other universities and research institutions worldwide. With a sustained effort in this project and many others, GCEP is helping to create a path toward an energy future that is feasible and practical, applicable to both the developed and the developing world, with much lower greenhouse gas emissions. GCEP projects fall into the "high-risk, high-reward" category where the goal is to invest in very challenging research with the potential to lead to large pay offs in a 10 to 50 year time frame.

* Global Climate and Energy Project, Stanford University

** Formerly at GCEP, now Google Switzerland GmbH This scientific review paper was drawn based on the invited speech by Professor Sally M. Benson at the 50th year anniversary of Japanese association of groundwater hydrology

*** Director of GCEP and Professor (Research), Department of Energy Resources Engineering, School of Earth Sciences, Stanford University 


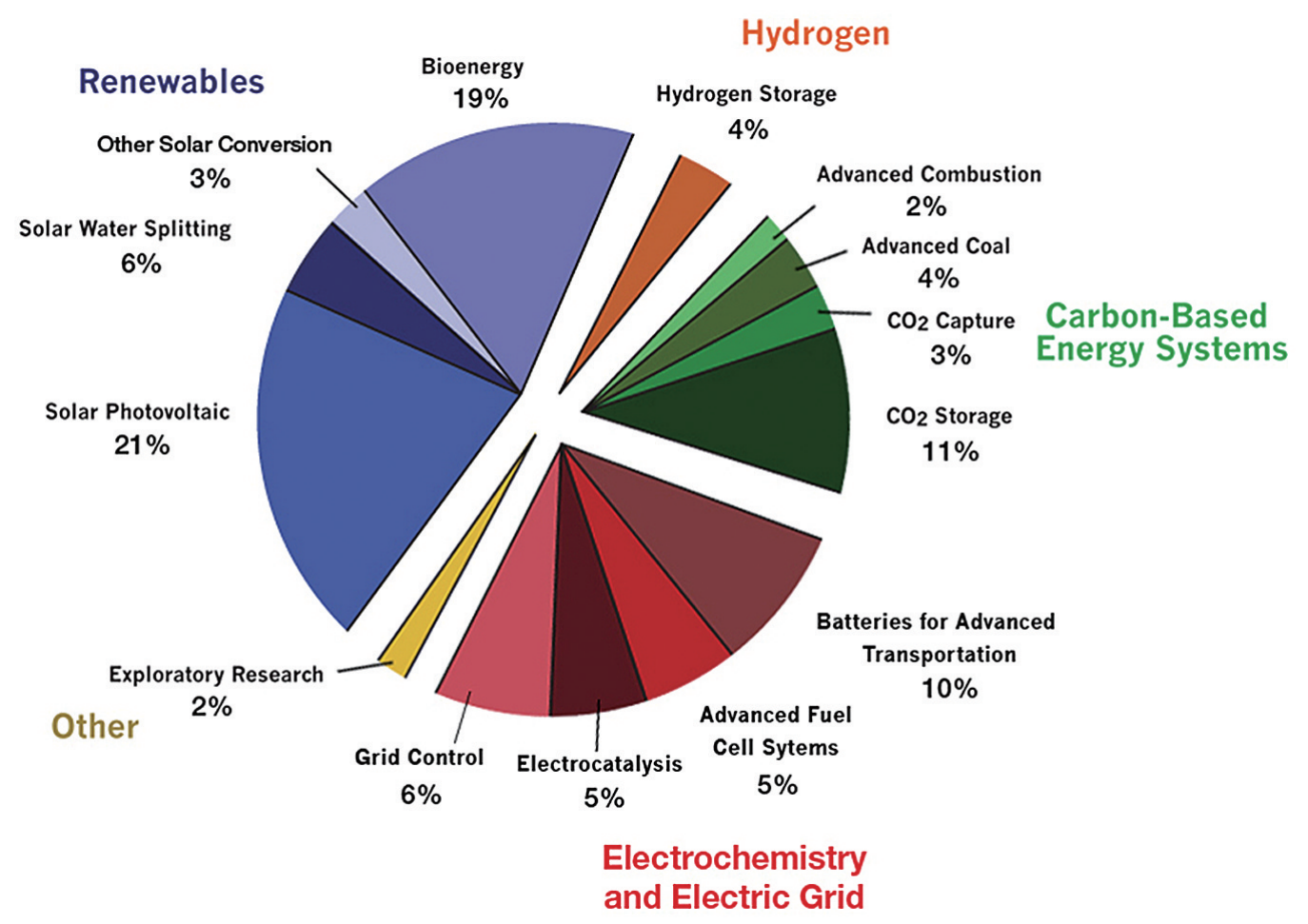

Figure 1 Pie chart showing GCEP portfolio of current ongoing projects, by research area, for the year 20092010 based on allocation of funds.

\section{GCEP Research Projects}

GCEP sponsors over 60 innovative research efforts that have the potential to be global solutions to significantly reduce greenhouse gas emissions that result from energy use. Figure 1 shows the broad portfolio approach of GCEP and how funds are distributed between different areas of energy research. More than 27 institutions worldwide participate in the GCEP program and researchers taking part are at the very top of their field. Each project averages 12 million dollars over a three year period and researchers have the opportunity to enhance their research through collaborations and interactions with researchers in other areas at the annual symposium held at Stanford University. Emphasis is placed on the involvement of graduate students and post-docs in carrying out the research and at GCEP events. The training of scientists and engineers in energy related technologies is a key aspect of the GCEP program, with the hope that they become the next generation of workforce and contributors in the area of energy technologies and sustainable deployment.

\section{GCEP Analysis Activities}

In the analysis area, the potential of processes and technologies to deliver useful energy and reduce greenhouse gas emissions is determined. The technology assessment team at GCEP evaluates the status and prospects of the energy areas included in the GCEP technology portfolio. The potential of the various energy resources and technologies to provide energy at a large scale and to enable the reduction of greenhouse gas concentration in the atmosphere is also assessed. This assessment includes considerations on resource availability and theoretical efficiency limits, and aims at identifying technol- 


\section{GCEP Global Exergy Flux, Reservoirs, and Destruction}

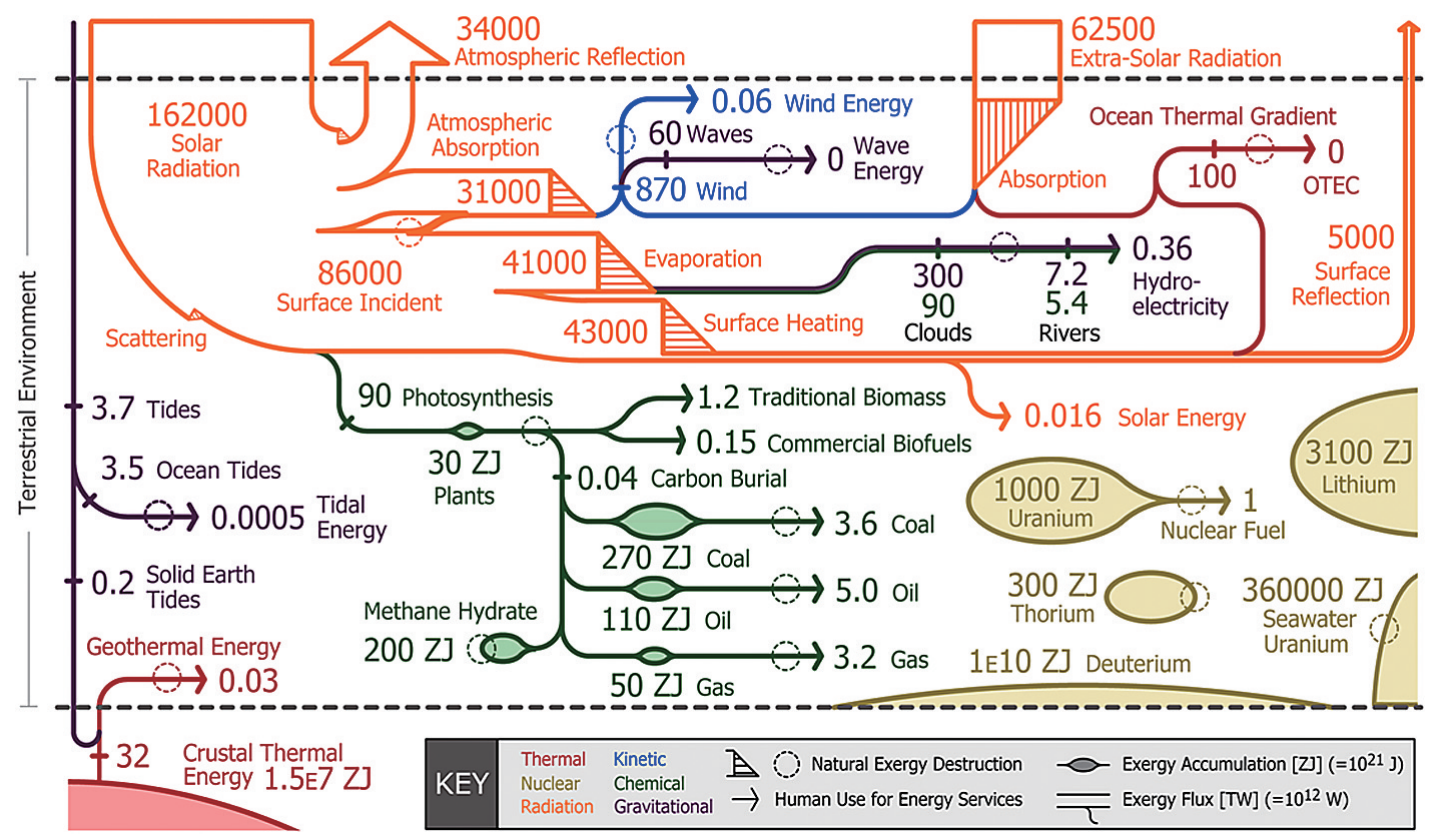

Figure 2 Resources chart, showing global exergy flux, reservoirs and destruction of exergy. (Herman, 2006; and Sassoon et al., 2009)

ogy barriers, step-out approaches, and opportunities for fundamental research related to a specific energy technology. Figure 2 shows the exergy resource chart made by Wes Herman and worked on by others at GCEP (Hermann, W.A., 2006; and Sassoon, R.E et al., 2009). This diagram summarizes the exergy reservoirs and flows in our sphere of influence including their interconnections, conversions, and eventual natural or anthropogenic destruction. Exergy is the useful portion of energy that allows us to do work and perform energy services. We gather exergy from energy-carrying substances in the natural world we call energy resources. While energy is conserved, the exergetic portion can be destroyed when it undergoes an energy conversion. Because the choice of energy resource and the method of resource utilization have environmental consequences, knowing the full range of energy options available to our growing world population and economy may assist in efforts to decouple energy use from environmental damage. Exergy and carbon flow charts that show quantities of available resources, and exergy destruction or carbon release associated with each energy transformation from acquisition of the resource to end use are available at http:/gcep. stanford.edu/research/exergy/flowchart.html.

Output of the technology assessment effort also includes workshops at Stanford and elsewhere that foster high-level discussion amongst experts about specific technologies, and reports to provide the energy community with updated analyses of the status and opportunities in energy areas. GCEP invites experts in the field for high level discussions of the state of research in a particular area. The goal of these workshops is to identify areas where fundamental research is needed to lead advances in energy technologies to allow deployment at large 
scale. Often these aspects are related to reducing exergy losses at some step in the process of energy use. Workshops sponsored by GCEP have included: Hydrogen; Solar Energy: Advanced Coal; Advanced Coal Technologies with $\mathrm{CO}_{2}$ Capture and Storage in China; Advanced Transportation; Fusion Energy; Fission Energy; Carbon Management in Manufacturing Industries; Non- $\mathrm{CO}_{2}$ Greenhouse Gas Emissions; Biological Capture and Utilization of $\mathrm{CO}_{2}$; and Caprocks and Seals for Geologic Carbon Sequestration. A full list of workshops and more information can be found through the GCEP website at http://gcep.stanford.edu/events/workshops.html.

These assessments have led to the identification of key factors that are barriers to deployment of an energy technology at large scale. For example, in the area of solar energy, lower costs and increased efficiency of solar photovoltaics and direct conversion of solar energy to fuel were identified as areas in need of fundamental research. In the bioenergy area, increasing the life-cycle efficiency of bioenergy production and identifying areas of land where biofuels can be grown and processed with large net greenhouse gas emission reductions is important. For energy storage, improving the performance and lowering the cost of grid-scale electricity storage to "firm" the intermittent renewable energy supplies, and increasing energy and power density and lifetimes of batteries for light-duty vehicle transportation were identified as areas of focus.

Increasing the efficiency of exergy transformations to bring them closer to their thermodynamic efficiency limit and identifying new exergy transformations with higher intrinsic efficiency (e.g. fuel cells) is important in the area of advanced energy conversions.

Some important factors for reducing emissions from fossil fuels with Carbon Dioxide Capture and Sequestration that need to be addressed are: reducing costs and energy requirements for
$\mathrm{CO}_{2}$ capture; increasing confidence in long term storage in saline aquifers; developing methods to effectively sequester $\mathrm{CO}_{2}$ in coal-beds while simultaneously increasing coal-bed methane production and identifying novel options for CCS where capture and geologic storage in sedimentary basins is not possible

A relatively new area for GCEP is Electricity Transmission and Distribution. The assessment of this area has led to new initiative to develop next-generation simulation tools and control technologies for electricity transmission and distribution with a large fraction of intermittent energy sources and grid-integrated storage.

Based on these assessments and findings GCEP has initiated research programs in the above areas and is currently actively investing in projects in all of these areas. The following gives a summary of some of GCEP projects in each area and possible areas of interest to GCEP in the future. All of these projects and GCEP activities can be found at the GCEP website at, http://gcep.stanford.edu/. Links to individual project results and publications from each project are also accessible through this website.

\section{Overview of GCEP Technical Areas}

\section{RENEWABLES}

\section{Solar Photovoltaic Electricity Production}

The solar energy flux reaching the Earth's surface represents a few thousand times the current use of primary energy by humans. The potential of this resource is enormous and makes solar energy a crucial component of a renewable energy portfolio aimed at reducing the global emissions of greenhouse gasses into the atmosphere. Nevertheless, the current use of this energy resource represents less than $1 \%$ of the total electricity production from renewable sources. Even though the deployment of photovoltaic systems has been increasing steadily for the last 20 years, solar technologies still suffer 
from some drawbacks that make them poorly competitive on an energy market dominated by fossil fuels: high capital cost, modest conversion efficiency, and intermittency. From a scientific and technical viewpoint, the development of new technologies with lower production costs is a key requirement for enabling the deployment of solar energy at a large scale. Increasing the conversion efficiency is also essential for sustaining cost reductions over the long term and for minimizing the environmental footprint of large scale, land intensive renewable energy projects.

Solar energy conversion is a central component of GCEP's renewable energy portfolio. New technologies with high conversion efficiencies and low production costs are required to enhance the deployment of solar energy. New photovoltaic concepts include the so-called "3rd generation PVs" that aim to achieve efficiencies approaching the thermodynamic limits for solar energy conversion, and organic-based thin films such as conjugated-polymer-based cells, that may substantially decrease the cost of photovoltaics. Other solar technologies are also considered, such as solar thermal and photoelectrochemical cycles.

One GCEP project is aimed at increasing the efficiency of solar cells using carbon nanotubes (CNT). This work is focused on the use of CNT's in a new generation of transparent electrodes. If successful this could lead to less costly, more efficient photovoltaic cells. The innovative synthesis process simultaneously selects optimal CNT types and directs structural organization of the CNT mesh during deposition, optimizing both the optical and electrical properties of the electrode. Unlike conventional opaque metal contact that cast shadows on the solar cell, the CNT electrodes are transparent and allow sunlight to pass through to the absorbing materials and still provide both efficient collection of the charges produced by photon absorption and charge transmissions to the exter- nal electric circuit (Hellstrom, S. L., et al., 2009).

\section{Bioenergy}

Biomass is a solar energy resource with potential to be a significant contributor to a renewable energy portfolio. It has a unique range of physical, chemical and biological parameters that sets it apart from fossil fuel analogs. However there are several barriers to deployment of biomass as an energy source in an environmentally benign way, on a global scale. One of the most important issues concerning use of biomass as an energy resource is the feasible deployment on a global scale, considering impacts of land use change, and water supply. In addition to this there are a number of areas that could benefit from research aimed at increasing efficiency of steps involved in the process. These include combustion, gasification, fuel synthesis, biological processes, crop growth, anaerobic digestion, and alcohol fermentation.

GCEP support research across most of these areas, including synthesis of biodiesel in microbes, increasing the efficiency of biological processing of lignocellulosics for biofuels synthesis, and biohydrogen production. Bioenergy projects not including the production of hydrogen from biological systems currently comprise 19\% of the cumulative GCEP portfolio. This is manifested from six projects, all related to biofuels. One such project was aimed at producing fatty acids for biodiesel from a bacterial system (http://gcep.stanford.edu/research/factsheets/microbial_synthesis.html). The other five projects are focused on biomass deployment and climate change (Field, C. B., et al., 2007; Campbell, J. E., et al., 2008, Loarie, S. R., et al., 2009; Lobell, D. B., et al., 2009, Loarie S. R., et al., 2009) and on modification of biomass feedstocks, for more efficient processing for biofuels production (http://gcep.stanford.edu/research/biomass.html).

Significant new findings have arisen from the work on the project "Biomass: the climate 
protective domain". A publication in the prestigious Science journal highlights the findings which show bioelectricity to be a more efficient use than ethanol production for biomass derived from corn (Campbell, J. E., et al., 2009). This interesting work not only highlights the importance for lifecycle analysis of biomass feedstocks and deployment from field to wheels but also the value of the GCEP research in the area of Bioenergy, Batteries for Advanced Transportation, and Advanced Combustion.

The four projects funded in the lignin area within Bioenergy are aimed at obtaining more efficient sugar release from biomass crops that are potentially more sustainable, environmentally friendly and potentially higher yielding than corn. The deployment of these crops on unused/abandoned agricultural land and the use of the glucose feedstock after release are key aspects to the value of the achievements of these projects. Based on current processing efficiencies turning this biomass into electricity for transportation gives more miles to the acre, however after considering efficiencies of processing that might be achieved through the GCEP projects, turning the new biomass crops into liquid fuels might make more sense in the longer term especially for modes of transportation that are difficult to electrify, including airplanes and ships.

One important point of note is that the lignin projects' goal of easier liberation of sugars (mainly glucose and xylose) is an extremely important one for all liquid transportation fuels, not just ethanol. The production of many different biofuels starts with glucose, including biodiesel, hydrogen, butanol, and methane. Indeed the highly successful work that achieved production of fatty acids in bacteria for biodiesel production requires a supply of glucose. In addition a scoping award was made to a project complimentary to the lignin management awards aimed at hydrolyzing the cellulose component of biomass.
GCEP have moved away from projects focused on ethanol production due to the growing recognition that other fuels make more sense in terms of efficiency of use and production. The portfolio is still largely focused on production of liquid transportation fuels, with the modification of feedstocks to allow efficient production and analysis to inform best case deployment and use of these biomass crops being key areas of research at present. Knowledge and technologies gained through GCEP bioenergy projects could allow biomass feedstocks to make a careful, sustainable, and significant contribution to our energy system as transportation fuel or electricity production.

\section{ENERGY STORAGE/ELECTROCHEMICAL TRANSFORMATIONS}

Energy storage is a key issue to be addressed to allow intermittent energy sources, typically renewable sources, to match energy supply with demand. There are numerous storage technologies that are capable of storing energy in various forms including kinetic energy, chemical solutions, magnetic fields, or other novel approaches. Improvements in the density and safety of carbon-free energy carriers such as electricity or hydrogen could foster the use of renewable energies in mobile applications.

$\mathrm{CO}_{2}$ emissions from the combustion of carbon-based fuels in transportation applications account for a quarter of global energy-related emissions, and the percent of global greenhouse gas emissions from transportation sources is expected to approach one third of all emissions in the coming decades. The impact of transportation on the environment may be reduced through the development of carbon-based fuels synthesized from low-carbon energy, the reduction of the amount of energy required for transportation, or by decoupling energy end-use from $\mathrm{CO}_{2}$ production. This last option encompasses the use of electric vehicles for ground transpor- 
tation in combination with stationary electricity generation using centralized carbon management technologies. With this goal in mind, the development of electric vehicles faces several significant technical challenges, including the development of batteries with high energy density and stability.

GCEP allocation in electrochemical cells, whether applied to fuel cells or batteries, has ranged between 12 to $15 \%$ of total funding. Currently three battery funded programs gear their research to the performance demands of all-electric vehicles for transportation.

Most of these cell concepts use lithium as the transporting ion and are investigating new chemistries and structures for the electrodes and/or electrolytes. Systems under study include abundant, low-cost, and high-capacity organic molecules and polymers electrochemically active towards Li, iron- and manganese-silicate compounds, and silicon.

\section{Batteries for Advanced Transportation}

This project studies novel electrode architectures based on close-packed nanowire arrangements. Compared to existing technologies using bulk electrodes, this approach has the potential to achieve five to seven times the energy density of lithium batteries. Nanowire devices provide a better ionic transport pathway because each nanowire is in direct contact with the electrolyte, forming a continuous pathway for electrons from the electrode collectors to the tips of the nanowires.

This feature, along with the large surface-tovolume ratio of the nanowires, enables full use of the theoretical charge capacity of the electrode material and increased speed of charging and discharging, resulting in higher energy and power density. Additionally, the proposed device architecture allows the use of high energy-density electrode materials that would be unstable in bulk configurations. For example, Li44 $\mathrm{Si}$ is a potential anode material with a very high specific energy capacity of $43,200 \mathrm{~kJ} / \mathrm{kg}$, but it is unstable in bulk configurations due to its large volume change (300\%) during charging/ discharging cycles. Structural stability can be provided by the proposed nanowire geometry and core/shell structure, where multiple thin shells are used to stabilize the $\mathrm{Li}_{4} 4 \mathrm{Si}$ core. In addition, the use of an ionically conducting but electronically insulating shell such as $\mathrm{SiO}_{2}$ may prevent interfacial chemical reactions between the electrode and the electrolyte, resulting in longer device lifetime (Chan, C. K., et al., 2008; Cui, LF., et al., 2009).

\section{Advanced Fuel Cell Systems}

Fuel cell programs with current GCEP funds address solid oxide fuel cells (SOFC). Both in theory and at the laboratory scale, SOFC's are capable of performing hydrocarbon to electricity conversion at almost twice the efficiency of widely deployed electricity generation equipment. But performance and cost have inhibited broader adoption of the technology into the market. Much of the work looks at nanostructuring the morphology of the membranes and interfaces to examining ways to improve performance at lower temperatures (Chueh W.C., et al., 2009).

The "electrocatalysis" area represents 5\% of the current total funding. At this time there is one active program in the GCEP portfolio, but a second one was awarded during the last proposal cycle and will start in early January, 2010. Projects in this area focus on the development of efficient catalysts for reduction and oxidation reactions aimed at either enabling directhydrocarbon fuel cells (Nakazawa, J., et al., 2008; Conley, N. R., et al., 2007; and McCrory, C. C. L., et al, 2007) or enhancing the kinetics of electrochemical systems for the production of hydrogen from water splitting.

Electrochemistry programs will remain a strong discipline in the GCEP portfolio because 
of the many complex fundamental chemical and physical processes involved with electrochemical cells. The lack of understanding at the atomic and molecular level drives many dimensions to be explored through models, theories, materials development, experimentation and cell optimization.

\section{Electric Grid}

A new effort in advanced electricity transmission and infrastructure began in late 2009 on grid network communication and control. This program is a large, multi-institution effort aimed at developing tools and methods that would allow a high penetration of renewable generation (up to 50\%) onto the electric grid. Strategies include a more intelligent grid, flatter hierarchy, bidirectional communication and control. Continued efforts are needed in the area of the advanced electricity transmission and infrastructure to include grid-scale storage and technologies that allow more power to be carried across existing transmission lines by lowering resistance, such as through superconductivity or carbon nanotubes.

\section{HYDROGEN}

\section{Hydrogen Production and Storage}

Currently the GCEP portfolio includes one project on Hydrogen storage which accounts for $4 \%$ of the whole. The goal of one of these projects is to develop a new energy storage device based on carbon-hydrogen bonds using single walled carbon nanotubes (SWCNTs). This work has led to a number of publications including "Hydrogen storage in carbon nanotubes through the formation of stable $\mathrm{C}-\mathrm{H}$ bonds" and "Energetics of $\mathrm{C}-\mathrm{H}$ Bonds Formed at Single-Walled Carbon Nanotubes" in NanoLetters (Nikitin, A., et al., 2008; and Nikitin, A., et al., 2009). In addition to the above project there are two exploratory projects in the hydrogen area, one on storage and one on hydrogen production. The project on hydrogen storage is aimed towards finding novel crystalline solids for high capacity molecular hydrogen storage. Pathways to synthesize materials near ambient conditions will be explored and chemical promoters which can be added to stabilize the structures will be investigated.

The project on biological production of hydrogen makes use of a cell free system designed by the researchers that makes use of enzymes from bacteria for hydrogen production from cellulosic hydrolysates. The goal is to realize an optimized system for high production rates in a bioreactor (Boyer, M. E., et al., 2006; Boyer M. E., et al, 2008).

\section{CARBON BASED ENERGY SYSTEMS}

Programs in carbon-based energy systems have received $30 \%$ of the cumulative distribution of GCEP funds to support 15 programs since the project inception. Currently, approximately $20 \%$ of GCEP funding goes towards this research which involves nine exploratory and full programs. At the core of this segment are programs in advanced combustion, carbon capture and $\mathrm{CO}_{2}$ sequestration. While there are examples of carbon capture and storage being practiced in commercial applications today, the technology options are not economically viable at the scale necessary to mitigate carbon emissions to the atmosphere. Thus GCEP consistently supports research under these themes to bring new innovations that greatly improve efficiency, performance, functionality and cost.

\section{Advanced Combustion}

Today, the majority of exergy contained in fossil fuels is not converted to useful energy services such as power generation and vehicle propulsion, but is instead converted to heat that is rejected into the atmosphere. Increasing the efficiency of primary exergy conversions could not only make better use of the fossil fuels, but also significantly reduce global $\mathrm{CO}_{2}$ emissions. 
Some GCEP funded researchers are developing and testing new engine architectures that can increase the exergy efficiency of single cycle engines to $60 \%$ by operating at extreme compression ratios. A follow-on project to this has the goal of completing studies of the fundamental combustion characteristics of these engines and providing a proof of concept that these high conversion efficiencies are achievable (Teh, K.-Y., 2008; and Teh, K.-Y., 2008).

\section{$\mathrm{CO}_{2}$ Capture and Storage}

In carbon capture, there are two programs aimed at developing new separation techniques and materials that improve the overall energetics of the process. One of these programs involves developing $\mathrm{CO}_{2}$ selective membranes for separating $\mathrm{H}_{2}$ from $\mathrm{CO}_{2}$ from a coal or biomass gasifier or a $\mathrm{CH}_{4}$ reformer with water-gas shift. Materials with an affinity for $\mathrm{CO}_{2}$ will be used to create a molecular gate that increases selectivity for $\mathrm{CO}_{2}$. Research will fabricate, test, analyze and model functionalized organic and inorganic membranes that are selective to the permeation of $\mathrm{CO}_{2}$. Tests show that polymers coated with alkali metal carbonates are promising for achieving the needed selectivity and permeance (http://gcep.stanford.edu/research/factsheets/ advsepmembranes.html). Nano-fabrication methods are also under development.

Two new exploratory proposals in the area of gas separations have also been initiated. In one, researchers will identify and test materials for carbon-ion transporting membranes that can be used for electrochemical separation of $\mathrm{CO}_{2}$. The other involves investigation of the feasibility of oxygen enrichment in air using plasmagenerated negatively charged oxygen ions in an axisymetric electric field.

A highly innovative project will investigate a fundamentally new coal conversion approach with no atmospheric emissions. Coal is first converted to syngas by supercritical water oxidation using water sourced from a saline aquifer. A combustor generates heat that is exchanged to a working fluid (He) which generates power. The combusted syngas (primarily $\mathrm{CO}_{2}$, water and $\mathrm{H}_{2} \mathrm{~S}$ ) is recombined with water from the brine and reinjected back into the saline aquifer. Benefits include no atmospheric emissions, injection of $\mathrm{CO}_{2}$ that is completely dissolved in the brine and higher overall energy efficiency ( 40\%) than competing alternatives (Heberle, J.R., and Edwards, C.F., 2009).

In the area of carbon sequestration in deep geological formations there are currently four active projects. One focuses on improving fundamental understanding of multiphase flow of $\mathrm{CO}_{2}$ and brine in sedimentary rocks. Multi-phase flow and trapping experiments of $\mathrm{CO}_{2}$ and brine are carried out using reservoir rocks and seals at reservoir conditions, under a range of flow rates and using different types of rocks that are likely to be used as storage reservoirs. X-ray CT scanning is used to examine sub-core scale transport and trapping processes. Data are interpreted using numerical simulation and history matching to elucidate the parameters and process that control brine displacement and trapping. The implications for storage capacity and leakage are investigated through the use of numerical simulation. In addition, approaches for monitoring leakage from sequestration projects using pressure measurements and carbon isotopes are also being developed (Michael Krause., et al., 2009; Perrin J-C., et al., 2009; Chabora, E. R., et al., 2009; and Silin, D., et al., 2009).

A new program initiated in 2009 is a multiinstitution effort in China to develop safe and effective methods for carbon sequestration in China's most promising saline aquifer sequestration sites. This effort involves 6 faculty members and 30 students and will focus on developing skills and fundamental hydrogeological and geochemical knowledge needed to sequester large 
volumes of $\mathrm{CO}_{2}$ (>200 $\mathrm{M}$ tonnes per project). A combination of laboratory experiments and numerical simulation will be conducted, focusing on key knowledge gaps for the specific geological settings in China.

A new project, initiated in early 2010, will focus on understanding how geochemical interactions between $\mathrm{CO}_{2}$, brine and the rock matrix can change the mechanical properties of the rock - which in turn influence seismic wave propagation. This research can have a profound influence on the interpretation of seismic data used to monitor the location $\mathrm{CO}_{2}$ plumes.

\section{GCEP Output and Achievements}

Over the six years that GCEP has been running, GCEP research has led to hundreds of peer reviewed publications and close to twenty patent applications. Over one hundred faculty investigators are now part of an interconnected community of international researchers in the energy field as a result of GCEP, and over three hundred graduate students and post-doctoral researchers have been involved in GCEP research.

\section{Next Steps for GCEP}

GCEP is currently supporting an impressive, broad portfolio of step-out approaches to capture, conversion, and utilization of solar energy. It is supporting novel approaches to solar thermal conversion systems, production of solar fuels, and organic/nanotechnology approaches to new materials and systems for solar cell designs.

In the near future GCEP will be looking to new areas and assessing the research opportunities. One area of focus nationally and internationally will be in solar energy conversion and utilization that would provide opportunities for enhanced GCEP activities, through the development of new concepts and ideas, would include the following:

a) Solar Thermal: these systems are considered "mature" by many technical experts. Although of- ten cited as the least expensive utility scale solar electricity technology, the "all-in" costs, and ability to get to scale, with current parabolic dish and other concentrated solar power systems are not at all clear, however.

b) Solar electricity: There are two broad approaches to obtaining step-out technologies for solar electricity production: significant (i.e., over 30 or $40 \%$ ) energy conversion efficiency improvements, through new physics; and significant cost reduction, at moderate (10-20\%) energy conversion efficiency, through new materials development.

c) Solar Fuels: Systems that offer integrated, or discrete storage, are receiving increasing attention at the national and international level, to attempt to close an existing enormous technical capability gap that is needed ultimately to enable a significant amount of global energy supply to be provided from intermittent renewable energy sources such as wind and solar. Development of storage technologies is thus crucial to enabling a long-term vision of a high penetration of renewables in the energy mix to become a reality.

Within the area of carbon based energy systems there are significant technical, economic and social/institutional challenges and opportunities. However the energy landscape, while heavily invested in carbon-based systems, is also evolving rapidly. Policy measures and consumer preference to increase end-use efficiency, renewable energy portfolio standards, feed-in tariffs, low carbon electricity generation standards and energy security driven policies have resulted in a dramatic slowing of investment in energy infrastructure for fossil-based energy supply. Moreover, uncertainties about future regulatory policies regarding carbon emissions have all but stopped investment in new fossil-based electricity generation. Likewise, if substantiated and shown to be cost-effective, increased natural gas reserves in the United States could decrease reliance on coal for electricity generation and cut related 
$\mathrm{CO}_{2}$ emissions by about 50\% — thus lessening the imperative to develop and deploy carbon capture and sequestration in the U.S. in the short term. Over the longer term, capture and sequestration of emissions from natural gas fired power plants may be required.

In this modern energy landscape, in economically developed regions of the world, fossil fuels will clearly need to compete for new investment based on superior economics, reliability and environmental performance - with environmental performance judged not only on atmospheric emissions of traditional air pollutants and greenhouse gases, but also on impacts and co-benefits of land use, water resources, groundwater quality and ecosystem preservation.

GCEP's near term goals are to seek out research opportunities aimed at: much more efficient technologies $(>60 \%)$ for conversion of fossil fuels to energy services such as electricity generation, vehicle propulsion systems, and thermal processing of materials; Efficient, low cost, multi-pollutant emissions reduction technologies, including $\mathrm{CO}_{2}$; Approaches for significantly reducing or eliminating water use during processing or conversion of fossil fuels; Efficient, low cost, low water use technologies for capturing dioxide from sources with a wide range of concentrations, from air concentrations of about $380 \mathrm{ppm}$ to in excess of 20\%; Energy efficient and low cost $\mathrm{CO}_{2}$ reuse; Improving fundamental understanding of sequestration security in saline aquifers and other sequestration options such as basalt, shale, and sub-seabed formations; and creative strategies and technologies for integrating fossil fuels with renewable energy supplies. In addition to these, GCEP will continue to seek out new needs and opportunities within the area of energy technology research with the ultimate goal of realizing deployment of greenhouse gas reducing technologies on a global scale.

\section{References}

Boyer M.E., Stapleton J.A., Kuchenreuther J.M., Wang C.W., and Swartz J.R., (2008) Cell-free synthesis and maturation of [FeFe] hydrogenases. Biotechnol Bioeng. 99(1): 59-67.

Boyer, M.E., Wang, C.-W., and Swartz, J.R., (2006). Simultaneous expression and maturation of the ironsulfur protein ferredoxin in a cell-free system., Biotechnology and Bioengineering. Vol. 94: 128-138.

Campbell, J.E., Lobell, D.B., and Field, C.B., (2009). Greater transportation energy and GHG offsets from bioelectricity than ethanol. Science. Vol. 324: 1055-1057.

Campbell, J.E., Lobell, D.B., Genova, R.C., and Field, C.B., (2008). The global potential of bioenergy on abandoned agriculture lands. Environmental Science Technology. Vol. 42: 579-5794.

Chabora, E.R., and Benson, S.M., (2009). Brine Displacement and Leakage Detection Using Pressure Measurements in Aquifers Overlying $\mathrm{CO} 2$ Storage Reservoirs. Energy Procedia. Vol. 1: 2405-2412.

Chan, C.K., Peng, H., Liu, G., Mcllwrath, K., Zhang, W.F., Huggins, R.A., and Cui, Y., (2008). High-performance lithium battery anodes using silicon nanowires. Nature Nanotechnology. Vol. 3: 31-35.

Chueh, W.C., and Haile, S.M., (2009). Electrochemical studies of capacitance in cerium oxide thin films and its relationship to anionic and electronic defect densities. Physical Chemistry Chemical Physics. Vol. 11, 8144-8148.

Conley, N.R., Labois, L.A., Pearson, D.M., McCrory, D.M., C., and Waymouth, R.M., (2007). Aerobic alcohol oxidation with cationic palladium complexes: Insights into catalyst design and decomposition. Organometallics. Vol. 26: 5447-5453.

Cui, L-F., Ruffo, R., Chan, C.K., Peng, H., and Cui., Y., (2009). Crystalline-amorphous core-shell silicon nanowires for high capacity and high current battery electrodes. Nano Letters. Vol. 9: 491-495.

Field, C.B., Campbell, J.E., and Lobell, D.B., (2008). Biomass energy: The scale of the potential resource. Trends in Ecology \& Evolution. Vol. 23: 65- 
72.

Heberle, J.R., and Edwards, C.F. (2009). Coal energy conversion with carbon sequestration via combustion in supercritical saline aquifer water. Energy Procedia. Vol. 1; 4055-4062.

Hellstrom, S.L., Lee, H.W., and Bao, Z., (2009). Polymer-assisted direct deposition of carbon nanotube bundle networks for high performance transparent electrodes. ACS Nano, Vol. 3: 423-1430.

Hermann, W.A., (2006). Quantifying global exergy resources. Energy. Vol. 31: 1685-1702.

Krause, M., Perrin, J-C., Kuo, C-W., and Benson, S.M., (2009). Characterization of $\mathrm{CO}_{2}$ storage properties using core analysis techniques and thin section data. Energy Procedia, Vol 1; 2969-2974.

Loarie, S.R., Asner, G.P. and Field, C.B., 2009. Boosted carbon emissions from Amazon deforestation. Geophysical Research Letters. Vol. 36: L14810.

Loarie, S.R, Duffy P.B., Hamilton, H., Asner, G.P., Field, C.B., and Ackerly, D.D., (2009). The velocity of climate change. Nature, Vol. 462; 24-31.

Lobell, D.B., Cassman, K.G., and Field, C.B., (2009). Crop yield gaps: their importance, magnitudes, and causes. Annual Review of Environment and Resources. Vol. 34: 179-204.

McCrory, C.C.L., Ottenwaelder, X.. Stack, T.D.P and Chidsey C.E.D.. (2007). Kinetic and mechanistic studies of the electrocatalytic reduction of $\mathrm{O}_{2}$ to $\mathrm{H}_{2} \mathrm{O}$ with mononuclear $\mathrm{Cu}$ complexes of substituted 1, 10-phenanthrolines. J. Phys. Chem. A. Vol. 111: 12641-12650.

Nakazawa, J., and Stack, T.D.P., (2008). Controlled Loadings in a Mesoporous Material: Click-on Silica, J. Am. Chem. Soc. Vol. 130: 14360-14365.

Nikitin, A., Zhang, Z.Y., Nilsson, A. (2009). Energetics of C-H Bonds Formed at Single-Walled Carbon
Nanotubes. Nano Lett. 9: 4, 1301-1306.

Nikitin, A., Li, X., Zhang, Z., Ogasawara, H., Dai, H., and Nilsson, A., (2008) Hydrogen Storage in Carbon Nanotubes through the Formation of Stable C-H Bonds. Nano Lett. Vol 8: 162-167.

Nikitin, A., Zhang, Z.Y., Nilsson, A. (2009). Energetics of C-H Bonds Formed at Single-Walled Carbon Nanotubes. Nano Lett. 9: 1301-1306.

Perrin, J-C., Krause, M., Kuo, C-W., Miljkovic, L., Chabora, E., and Benson, S.M., (2009). Core-scale experimental study of relative permeability properties of $\mathrm{CO}_{2}$ and brine in reservoir rocks, Energy Procedia. Vol. 1; 3515-3522.

Sassoon, R.E., Hermann, W.A., Hsiao, I-C., Milkovic, L., Simon, A.J., Benson, S.M., (2009). Quantifying the Flow of Exergy and Carbon through the Natural and Human Systems, in Materials for Renewable Energy at the Society and Technology Nexus, edited by Reuben T. Collins (Mater. Res. Soc. Symp. Proc. Volume 1170E, Warrendale, PA, 2009), 1170-R01-03.

Silin, D., Patzek, Y., and Benson, S.M., (2009). A model of buoyancy-driven two-phase countercurrent fluid flow. Transport in Porous Media. Vol. 76: 449469.

Teh, K.-Y., Miller, S.L., and Edwards, C.F., (2008). Thermodynamic Requirements for Maximum IC Engine Cycle Efficiency (I): Optimal Combustion Strategy. International Journal of Engine Research. Vol. 9: 449-466.

Teh, K.-Y., Miller, S.L., and Edwards, C.F., (2008). Thermodynamic Requirements for Maximum IC Engine Cycle Efficiency (II): Work Extraction and Reactant Preparation Strategies. International Journal of Engine Research. Vol. 9: 467-481.

(Received May 17, 2010, Accepted June 10, 2010) 